\title{
Dealing with risk and uncertainty in irrigation water management: an Australian perspective
}

\author{
Z. Paydar ${ }^{1} \&$ E. Qureshi ${ }^{2}$ \\ ${ }^{I}$ CSIRO Land and Water, Canberra, Australia \\ ${ }^{2}$ CSIRO Ecosystem Sciences, Canberra, Australia
}

\begin{abstract}
With increasing pressure on limited water resources, water managers and policy makers face many challenges to meet various, often conflicting, demands with limited resources and much uncertainty (e.g. climate change) and often lack effective tools to investigate different options under uncertain conditions. The recent studies in the Murray Darling Basin have highlighted that there will be less water available in the future in many parts of the Basin which introduces a large uncertainty for the future of irrigation. However, the water sector lacks a robust approach to quantify the risks and criteria for system resilience and thresholds for setting up risk management strategies. Adopting the basic idea of spreading the risk from the field of finance, the "Portfolio Theory" can be used in quantifying the risk against uncertainties associated with each option dealing with water scarcity. The aim of this analytical approach is to increase adaptive capacity of the system by diversifying options and mitigating the associated risk and choosing more robust portfolios. In this paper, a range of options (e.g. retiring land from irrigation, water savings measures, ground/surface water conjunctive use, use of alternative water for irrigation) are considered and ways of applying the "Portfolio Theory" are explored to formulate a risk-based approach to water demand management and planning with diversified options to deal with uncertain supply sources.
\end{abstract}

Keywords: Portfolio Theory, irrigation, risk, uncertainty, drought.

\section{Introduction}

Water allocations in the south eastern parts of Australia have been reduced since 2006 due to the prolonged drought. Climate change is expected to reduce water 
availability in the southern part of the Murray Darling Basin in the future [3]. Implications for the water managers would be to deal with less water in the future. The recently released Guide to the proposed Basin plan [13] proposes significant reductions to diversion limits for irrigation water use to achieve a sustainable environmental and consumptive use outcome. This means the irrigation industry needs to adapt strategies to manage risks in an uncertain future with less water available. There seems to be a need for a robust method for quantifying risks and benefits of assessing options to cope with reduced water allocations in the uncertain future.

In the field of corporate finance several approaches to risk management exist that are used mainly for investment decisions. One approach that addresses risk reduction through diversification of investment [11] called "Portfolio Theory" offers applications to water sector that have yet to be explored. Although some application of the Portfolio Theory to the water supply and natural resource management $[5,8,12,18]$ have shown useful examples of increasing the reliability of water supply and making decisions in natural resource management, the theory has not been explored for the irrigation management in dry and uncertain conditions.

Here we explore a risk-based approach (from Portfolio Theory) to demand management and planning with diversified options to deal with variable and uncertain available water for irrigation. Options and strategies for irrigators for coping with less available water allocations are first explored. The risks and returns of each individual option as well as the mix of different options are then considered and ways of applying the "Portfolio Theory" are explored to formulate a risk-based approach to demand management and planning with diversified options to deal with uncertain supply sources.

\subsection{Adaptation strategies}

For irrigators to cope with reduced water allocations there exist several options based on previous experience, the farm location, the size of the enterprise, the market and access to extra water sources. One strategy involves retiring (all or part of) the land from irrigation permanently. This option might require selling the water entitlements (buy back for the environment), and conversion to dryland agriculture when allocated water is not enough to irrigate the whole irrigated area.

Adopting water savings measures is an obvious option to reduce losses and increase irrigation efficiency. This includes reduction of evaporation and seepage losses from irrigation channels and storages by covering or other means, lining the channels or replacing with pipes which require investments in infrastructure improvements. Conversion from surface irrigation application methods to more efficient pressurised systems (e.g. drip, sprinkler) is another way of saving water on irrigated farms. Other water management options (e.g. deficit irrigation, partial root zone drying and irrigation scheduling) can also play important roles in trying to get more yields per drop of water. 
Decline in water availability has resulted in new directions to use alternative sources of water. This includes conjunctive use of groundwater and surface water, use of less suitable water (more saline) and recycling agricultural drainage water. Conjunctive water use (surface and groundwater) plays an important role in reducing risks associated with uncertain surface water supplies and their variability. Groundwater brings stability in water supplies, during the drought years to meet the demands of consumptive users. With decreased water allocations, drainage reuse is most likely to supplement the allocation supply. On-farm storage and recycle systems capture surface drainage from irrigation and rainfall to provide an alternative water supply and therefore increasing water use efficiency.

There are also options regarding the crop selection and mix that can mitigate the risk and benefit the irrigators. Some of the above strategies can be adopted at the farm level and some can be adopted at the irrigation system level as a coordinated approach to dealing with less available water.

\section{Formulation of the problem}

Modern Portfolio Theory, developed in the 1950s is often applied by financial managers in investing in different assets (or portfolios of assets). The theory shows that diversification in the choice of investments is sensible and reduces the variance (risk) of investment [11]. This expected return-variance rule implies the superiority of diversified portfolio. In trying to make the variance small (less risky), it is not enough to invest in many options which could be highly positively correlated. The lower the correlation of returns between investments, the larger the benefits of diversification will be. The expected returns of the individual investment options, their standard deviations (risks) and the correlation between the investment options are central to the Portfolio Theory.

In general terms, the expected return $\mathrm{E}\left(\mathrm{R}_{i}\right)$ of an option $i(i=1, \ldots n)$ is given by:

$$
E\left(R_{i}\right)=\sum_{k=1}^{m} p_{k}\left(R_{i k}\right)
$$

where $\mathrm{R}_{i k}$ is the return of the investment option $i$ with a set of given scenarios $k$ $(k=1, \ldots, m), \mathrm{p}_{k}$ is the probability that a scenario $k$ occurs and $m$ is the total number of scenarios.

The variance of an option $i$ 's return is:

$$
V a r_{i}=\sum_{k=1}^{m} p_{k}\left(R_{i k}-E\left(R_{i}\right)\right)^{2}
$$

In corporate financial terms, risk is the deviation of expected return from mean or expected value, thus square root of the variance (standard deviation) is considered as risk. 
The expected return $\mathrm{E}\left(\mathrm{R}_{p}\right)$ of a portfolio of $n$ investment options is simply a weighted average of the return of the individual investments:

$$
E\left(R_{p}\right)=\sum_{i=1}^{n} w_{i} E\left(R_{i}\right)
$$

where $w$ is the share (weighting) of an investment option $i$ within the portfolio $p$. The risk of a portfolio $\sigma_{p}$ is given by:

$$
\sigma_{p}=\operatorname{SQRT}\left(\sum_{i=1}^{n} w^{2} \sigma_{i}^{2}+\sum_{i=1}^{n} \sum_{j=1}^{n} w_{i} w_{j} \sigma_{i} \sigma_{j} \rho_{i j}\right)
$$

$\rho_{i j}$ is the correlation between two investment options $i$ and $j$ and is determined by the covariance between these two options $i$ and $j$.

\section{Case study: Murrumbidgee Irrigation Area (MIA)}

A hypothetical area resembling the Murrumbidgee Irrigation Area (MIA) in New South Wales has been chosen for demonstrating the applicability of the methodology.

For the adaptation strategies available at the irrigation district level, four investment options were considered as: 1- the retiring land from irrigation (i.e. selling of water entitlements), 2-investng in water savings measures, 3conjunctive use of groundwater/ surface water and 4- drainage recycling and reuse option. For illustrative purposes we concentrate on these simplified options only.

The uncertainty is considered here as changes in surface water diversions and irrigation water availability as a result of climate variability based on historical records. Water diversion data for Murrumbidgee in CSIRO Sustainable Yield project [3] based on 111 years of historical water diversion data obtained and utilised by Qureshi et al. [16] in their economic analysis (after adjustments and deduction of other uses to represent irrigation diversion) were used in the current study. The data were ranked from the lowest to the highest diversions into four scenarios (very low, low, high and very high) with the probabilities of $0.12,0.38$, 0.38 and 0.12 respectively.

For each scenario the estimated percentage reduction from the base case scenario (i.e. average of all years) was considered following the results of the economic modelling [16] that studied the economic impact of the irrigation water reductions in the Murrumbidgee region. Table 1 lists the data extracted from that modelling for the scenarios and used in this analysis.

In arriving at returns from each option (and the four scenarios) and their risks, the whole irrigation area (or district) was considered in the analysis.

Option (1) consists of selling parts of the water entitlements (i.e. permanent sale to an environmental water holder) and retiring land from irrigation 
permanently and converting to dryland agriculture (Xha) with cereals production. Total net return in this option can be estimated from the revenues from selling the entitlements (annualised) plus the added benefit from the converted irrigated land to dryland cereals production, and the profit from the remaining land under irrigation. Eqn. (5) describes the relationship for this option, assuming the volume of water sold will equal reductions in diversions according to Table 1.

Net return $(\$ /$ year $)=$ Revenue (annualised) from

sold water entitlements -annualised (\$/year) + Profit in dryland (\$/ha/year * Xha)

+ Profit in irrigated production $[\$ /$ ha/year $*($ remaining land $)]$

Table 1: $\%$ changes from the base case in Murrumbidgee region (extracted from [16]).

\begin{tabular}{|c|c|c|c|c|c|}
\hline Scenario & $\begin{array}{c}\% \\
\text { reduction } \\
\text { in irrigated } \\
\text { land }\end{array}$ & $\begin{array}{c}\text { Profit } \\
\text { from } \\
\text { irrigation } \\
(\$ / \mathrm{ML}) * *\end{array}$ & $\begin{array}{c}\text { Price of } \\
\text { water } \\
\text { entitlement } \\
(\$ / \mathrm{ML}) *\end{array}$ & $\begin{array}{c}\% \text { change } \\
\text { in } \\
\text { diversions }\end{array}$ & $\begin{array}{c}\% \text { change } \\
\text { in } \\
\text { irrigation } \\
\text { profit }\end{array}$ \\
\hline V. low & 11 & 212 & 1175 & -27 & -18 \\
\hline Low & 1 & 198 & 100 & -6.8 & -2.2 \\
\hline High & & 182 & & +8.8 & +5 \\
\hline V. high & & 169 & & +21 & +8.4 \\
\hline
\end{tabular}

* from [4]

$* *$ from [16]

The data and assumption for the base case scenario are listed in Table 2.

Table 2: $\quad$ Base case data used for MIA.

\begin{tabular}{|c|c|c|c|c|}
\hline $\begin{array}{c}\text { Area } \\
(\mathrm{ha})^{* *}\end{array}$ & $\begin{array}{c}\text { Diversions } \\
(\mathrm{ML}) * *\end{array}$ & $\begin{array}{c}\text { Total } \\
\text { irrigation } \\
\text { profit } \\
(\$ / \text { year }) * *\end{array}$ & $\begin{array}{c}\text { Profit from } \\
\text { irrigation } \\
(\$ / \mathrm{ML}) * *\end{array}$ & $\begin{array}{c}\text { Profit } \\
\text { from } \\
\text { dryland } \\
- \text { wheat } \\
(\$ / \mathrm{ML})\end{array}$ \\
\hline 156,000 & $1,048,000$ & $322,125,308$ & 198 & 100 \\
\hline
\end{tabular}

** from [9]

Option (2) considers investing in water saving measures which at the irrigation area (district) level may consist of fixing the leaky parts of the irrigation channels and reducing evaporation losses from storages by improving the efficiency or reducing surface areas. Previous study in this area [15] showed that lining $500 \mathrm{~km}$ of leaky channels would require an investment of $\$ 150 \mathrm{~m}$ and would save up to 40GL of water. A combination of concrete, earth, rice hull ash and water sludge lining was considered. Also an investment on Barren Box Swamp redevelopment would involve improving the efficiency of the shallow 
basin by splitting it into deeper and more useable cells. It was estimated that this would require a $\$ 30 \mathrm{~m}$ investment and would save up 20-30 GL of water [15].

The water saved from these measures was considered to be used for irrigation in the same irrigation area and total net return for this option is calculated from the annual profit from the saved water and total estimated profit from irrigation in each scenario (using Tables 1 and 2) according to eqn. (6).

Net return $(\$ /$ year $)=$ Revenue from the total saved water $(\$ /$ year $)$

- Annualised costs of water savings (\$/year)

+ Total irrigation profit (without water savings-\$/year)

Option (3) is the conjunctive use of groundwater and surface water. The economic return for each scenario was estimated using the results of a previous study of economics of conjunctive water use at the farm level [7] in Coleambally Irrigation Area which is in the Murrumbidgee region as MIA. Based on modelling salinity effect on production of four farms, the results were reported as total gross margin at different water allocation levels. Assuming the same \% reduction of allocations at the farm level as in Table 1, for each scenario, the average gross margin [7] was assumed for a typical farm of 220ha. To aggregate this farm analysis to the irrigation area, a total number of 20 farms with access to groundwater (within MIA boundary) were considered. In MIA, the areas with low salinity groundwater are small and so there is little potential to use groundwater as a resource for irrigation [14]. Total groundwater entitlements are about $18 \mathrm{GL}$ and current groundwater abstraction is about 5GL. Assuming a total of about 10 extra GL of groundwater abstraction with a pumping cost of $\$ 7 / \mathrm{ML}$ [16] and also assuming that most of the capital investment for pump and installations are already made and no groundwater use in wetter scenarios, the total net return for each scenario of this option would be:

Net return $(\$ /$ year $)=$ Total irrigation profit (without this option-\$/year) - Capital costs (annualised) - Pumping costs (\$/year)

+ Gross margin of conjunctive use (\$/year)

Option (4) is for investing in capturing, storing and recycling drainage water from the farms. This can be conducted in a coordinated way at the district level. The cost estimations are based on a $20 \%$ of water applied as drainage, $\$ 40 / \mathrm{ML}$ of costs [15] and returns are for each scenario as water allocations. The extra volume of water recaptured is considered to be used for irrigation in the same irrigation area and the net return for this investment option is estimated according to eqn. (8).

Net return (\$/year) $=$ Total irrigation profit (without recycling-\$/year) - Annual costs (\$/year) + Revenue from recycled water (\$/year)

The total net returns for each scenario of each option are estimated according to eqns. (5) to (8). Applying eqns. (1) and (2) then gives the risk and expected return for each option. 
Assuming, for simplicity, that the four options are mutually exclusive and independent (i.e. no covariance between them is considered), eqn. (4) simplifies a great deal. We can then construct different portfolios using different shares (weights) of each option and estimate the expected return and risk of each portfolio according to eqns. (3) and (4). Changing the value of $w(0=<w<=1)$ randomly in eqns. (3) and (4) will produce different portfolios with different shares of investment options that can be compared in a risk- return profile (e.g. one portfolio can be composed of 0.4 of total investments in selling water entitlement; 0.2 of water savings; 0.1 in conjunctive use of water and 0.3 in drainage recycling). Some of the portfolios may not be physically plausible in MIA because of physical limitations (e.g. investing in a small proportion of? redevelopment of Barren Box Swamp may not be possible since the redevelopment would need a certain minimum capital investment). For the purpose of illustrating the methodology no constraints as the proportions of options or the maximum investment are considered for this analysis.

\section{Results: portfolio selection}

Table 3 gives the results of the above calculations for all the options considered in this analysis. The risk-return characteristics of different portfolios were then calculated using the estimates for each option in Table 3 with different $w$ values in eqns. (3) and (4). When mapped for a number of possible portfolios, using random proportions (shares) of each of the four options and performing the riskreturn computations, the resulting graph (Fig. 1) shows a picture of risk of portfolios. Each point in the graph represents a possible portfolio consisting of different proportions of the four investment options described before. The curve in Figure 1 shows the "efficient frontier" representing the different portfolios that are attainable by the investor (the irrigation district in this case study).

The risk level is at minimum (minimum variance portfolio) with certain combination of investments which might be desirable under some circumstances (area A in Fig. 1). The power of diversification (area A) is shown by the risk of portfolios being lower than the risk of each individual investment option (areas B and $\mathrm{C}$ ). The minimum variance portfolio is where the maximum effect of diversification can be achieved.

In case of the Murrumbidgee Irrigation Area, the trend for highest return and highest risk portfolios is towards investing high proportions (more than $70 \%$ of the total investment) on the option of drainage recycling (area B in Fig. 1).The minimum risk level (area A) comprised of portfolios with almost equal shares in all four options (demonstrating the benefit of diversification). Higher returns are possible (as shown by points between areas A and B in Fig. 1) but with higher risk when there are more shares of retiring land and drainage recycling options and less in the other two investment options (i.e. water savings and conjunctive use). Also lower returns and lower risks are gained with portfolios with higher shares $(>70 \%)$ in the retiring land option and no investment in drainage recycling. Area $\mathrm{C}$ in Fig. 1 shows the lowest returns and high risks when almost all the investments are either in water savings or conjunctive use of surface 
/groundwater. The decision to switch to a diversified portfolio can reduce the variability in expected returns (risks) up to $57 \%$, but it can also reduce the total returns by $6 \%$ (or $\$ 134 / \mathrm{ha}$ ). Over all, this preliminary analysis suggests that investing in option (4) is very risky, but with high return, option (1) can be less risky but with a combination of all four options having equal shares in the investment portfolio the risk can be minimised.

For the MIA case study, the options of water savings and conjunctive use investments might not be as attractive as the other two options mainly because of the limited capacity for these two options in this irrigation area. Other investment options can also be included in the analysis (e.g. on-farm water savings, crop mix or water trading) that can enhance the range of possible portfolios and might show more benefits from diversification.

Table 3: Investment options with risks and returns in MIA.

\begin{tabular}{|c|c|c|}
\hline Option & Expected Return of option & Option risk \\
\hline (1) Retiring land & $\$ 325,217,540$ & $\$ 18,239,072$ \\
\hline (2) Water saving measures & $\$ 322,425,328$ & $\$ 23,908,709$ \\
\hline (3) Conjunctive use -SW/ GW & $\$ 322,915,458$ & $\$ 23,903,992$ \\
\hline (4) Recycling and storage & $\$ 350,146,501$ & $\$ 26,303,319$ \\
\hline
\end{tabular}

The resulting risk-return characteristic can be used as a tool for investment decision making depending on the desired level of risk taking and the expected return. For a given level of risk the graph shows where the maximum return is expected (the top curve).

\section{Conclusions}

A method for calculating the risk profile for a variable and uncertain water allocation for irrigation has been presented that is based on Portfolio Theory and suitable for practical application in irrigation investment decision making. 


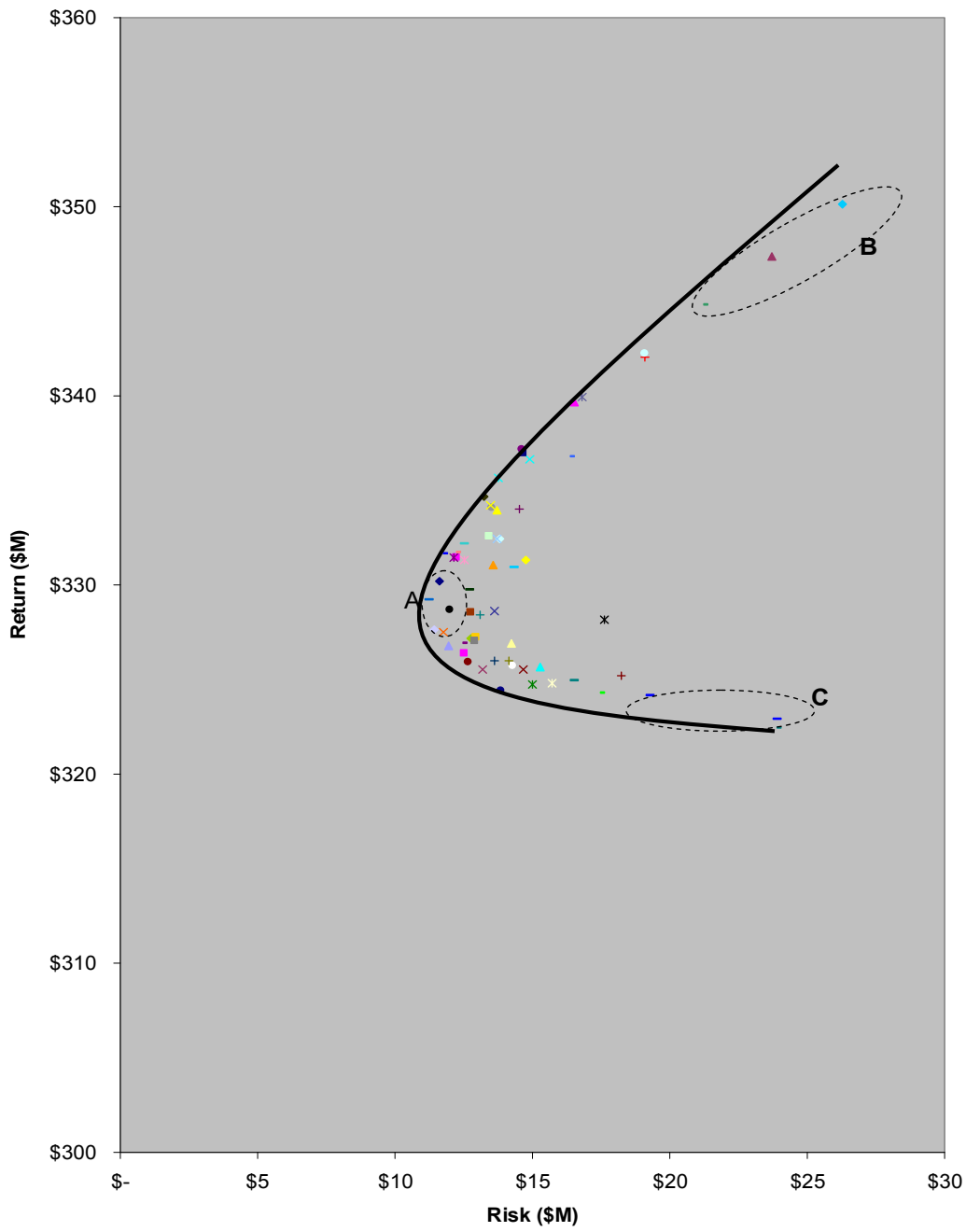

Figure 1: Possible portfolio of investment options in MIA (points present different portfolios).

The case study for Murrumbidgee shows the application of this method and demonstrates the risk reduction benefit of diversifying management options in a reduced water allocation conditions, predicted in the south eastern part of Australia.

The developed method can be used to identify opportunities to maximise reliability (minimising risk) for a given level of investment (return) or maximise return for any given (desired) level of risk, depending on risk-taking characteristics. 
The benefits of this risk-based approach are the quantification of risk for a system with diversified options and improved confidence in reliability of different investment decisions (options) in the irrigation community under uncertain conditions.

Further development of this analysis into a decision support toolkit can provide a scientific basis for supporting adaptation planning at different scales. This offers a significant opportunity for strengthening drought risk analysis as well as planning that can be used by the districts or farmers.

\section{References}

[1] Australian Bureau of Agricultural and Resource Economics - Bureau of Rural Sciences, Environmentally sustainable diversion limits in the Murray-Darling Basin: socioeconomic analysis, report to the Murray-Darling Basin Authority, Canberra, 2010.

[2] Clemen, R. T., Making hard decisions: An introduction to decision analysis, 2nd Ed., Brooks/Cole: Pacific Grove, Calif.,1996

[3] CSIRO. The Murray darling Basin Sustainable Yields Project. Overview and reports available at http://www.csiro.au/partnershps/MDBSY.html, 2008.

[4] Department of the Environment, Water, Heritage and the Arts, Review of the 2007-2008 water entitlement purchases, Final Report (AA001526), Hyder Consulting, Canberra, 2008.

[5] Figge, F., Bio-Folio: applying portfolio theory to biodiversity. Biodiversity and Conservation, 13, pp. 827-849, 2004.

[6] Han, S., Diekmann, J., Lee, Y., Ock, J., Multicriteria financial portfolio risk management for international projects. Journal of Construction Engineering and Management, 130 (3), pp. 346-356, 2004.

[7] Hirsi, I., Economics of conjunctive water management under crop salinity tolerance constraints. A thesis submitted for the degree of Doctor of Philosophy in Environmental Sciences. Faculty of Science, School of Environmental Sciences, Charles Sturt University, 2008.

[8] Hyde KM, Maier HR, Colby CB, Reliability-based approach to multicriteria decision analysis for water resources. $J$ Water Resour Plan Manage, 130(6), pp. 429-438, 2004.

[9] Khan, S., Akbar, S., Rana, T., Abbas, A., Robinson, D., Paydar, Z., Dassanayke, D., Hirsi, I., Blackwell, J., Xevi, E. and Carmichael, A., Offand on-farm savings of irrigation water. Murrumbidgee valley water efficiency feasibility project, Water for a Healthy Country Flagship report, CSIRO, Canberra, 2005.

[10] Keefer, D., and Bodily, S. E., Three point approximations for continuous random variables. Manage. Sci., 29, pp. 595-609, 1983.

[11] Markowitz H.M., Portfolio selection. Journal of Finance, 7, pp. 77-91, 1952. 
[12] Marinoni, O., Adkins, P. \& Hajkowicz, S., Water planning in a changing climate: Joint application of cost-utility analysis and modern Portfolio theory. Environmental Modelling \& Software, 26, pp. 18-29, 2011.

[13] Murray-Darling Basin Authority, Guide to the proposed Basin Plan: Overview, Murray-Darling Basin Authority, Canberra, 2010.

[14] Murrumbidgee Irrigation. Groundwater conditions in the MIA, report prepared by A. van der Lely, 2009.

[15] Pratt Water, The Business of Saving Water. The Report of the Murrumbidgee Valley Water Efficiency Feasibility Project, Pratt Water Ltd: Campbellfield, Victoria, 152pp, 2004.

[16] Qureshi, ME., Connor, J., \& others, Impact of climate change on the southern Murray-Darling Basin, Australia, working paper, CSIRO Ecosystem Sciences, 2011.

[17] Robinson, DW, Construction and operating costs of groundwater pumps for irrigation in the Riverine Plain, CSIRO Land and Water Technical Report 20/02, CSIRO Land and Water, Canberra, 2002.

[18] Wolff, G., Calculating constant-reliability water supply unit costs. Water Policy, 10, pp. 95-104, 2008. 